\title{
Ultrasound-Assisted Multi-Enzymatic System for the Preparation of ACE Inhibitory Peptides with Low Bitterness from Corn Gluten Meal
}

\author{
Shanfen Huang ${ }^{1,+}$, Yunliang $\mathrm{Li}^{2, *}{ }^{+}$, Chengliang $\mathrm{Li}^{3, \ddagger} \mathbb{D}$, Siyu Ruan ${ }^{2}$, Wenjuan Qu ${ }^{2}$, Yanhua Ding ${ }^{2}$, Xiaofei Ye ${ }^{4}(\mathbb{D}$ \\ and Haile $\mathrm{Ma}^{2, *}$
}

check for

updates

Citation: Huang, S.; Li, Y.; Li, C.; Ruan, S.; Qu, W.; Ding, Y.; Ye, X.; Ma, H. Ultrasound-Assisted

Multi-Enzymatic System for the Preparation of ACE Inhibitory Peptides with Low Bitterness from Corn Gluten Meal. Processes 2021, 9 , 2170. https://doi.org/10.3390/ pr9122170

Academic Editor: Anet Režek Jambrak

Received: 5 November 2021 Accepted: 29 November 2021 Published: 2 December 2021

Publisher's Note: MDPI stays neutral with regard to jurisdictional claims in published maps and institutional affiliations.

Copyright: (c) 2021 by the authors. Licensee MDPI, Basel, Switzerland. This article is an open access article distributed under the terms and conditions of the Creative Commons Attribution (CC BY) license (https:// creativecommons.org/licenses/by/ $4.0 /)$.
1 School of Biology and Food Engineering, Chuzhou University, Chuzhou 239000, China; hsf7892021@163.com

2 School of Food and Biological Engineering, Jiangsu University, Zhenjiang 212013, China; siyuruan@126.com (S.R.); wqu@ujs.edu.cn (W.Q.); dyh2099@163.com (Y.D.)

3 Key Laboratory of Environment Correlative Dietology, College of Food Science and Technology, Huazhong Agricultural University, Ministry of Education, Wuhan 430070, China; LCL0718@hotmail.com

4 Department of Biosystems Engineering and Soil Science, The University of Tennessee, Knoxville, TN 37996, USA; xye2@utk.edu

* Correspondence: liyunliang@ujs.edu.cn (Y.L.); mhl@ujs.edu.cn (H.M.)

+ These authors contributed equally to this study.

$\ddagger$ Present address: Instituto de Agroquímica y Tecnología de Alimentos (IATA-CSIC), 46980 Paterna, Valencia, Spain.

\begin{abstract}
The promising angiotensin converting enzyme (ACE) inhibitory peptides derived from corn protein usually have strong bitterness and thus limit their use among consumers. To prepare ACE inhibitory peptides with low bitterness, two energy-efficient types of ultrasound pretreatment were introduced into the multi-enzymatic system of corn gluten meal. The results showed that Flavourzyme-Protamex sequential enzymolysis produced the peptides with high ACE inhibitory activity and the lowest bitterness compared with other enzymolysis conditions. During the optimized sequential enzymolysis, the divergent ultrasound pretreatment with a frequency of $40 \mathrm{kHz}$ for $60 \mathrm{~min}$ exhibited higher ACE inhibitory activity (65.36\%, accounting for $73.84 \%$ of the highest ACE inhibitory activity) and lower bitterness intensity of peptides, compared with an energy-gathered ultrasound. The results of the study showed that, on the one hand, divergent ultrasound pretreatment induced the highest intrinsic fluorescence of protein, with more hydrophobic amino acid residues exposed for cleavage by exopeptidases, which leads to a reduction in bitterness. On the other hand, the amino acid composition analysis proved that more Tyr, Ile, and Val moieties, instead of Leu (bitterest substance), and more peptide fractions with a molecular weight $>1000$ Da should be the structural features of high ACE inhibitory peptides.
\end{abstract}

Keywords: corn gluten meal; ACE inhibitory activity; bitterness; ultrasound pretreatment; enzymatic hydrolysis; peptides

\section{Introduction}

Corn has an eminent position in food crops across the world. Corn gluten meal is the major by-product of the corn starch process [1]. It contains approximately $60 \%$ protein that is high in hydrophobic amino acids, particularly Glu, Leu, Pro, and Phe [2], making it ideal for the preparation of angiotensin converting enzyme (ACE) inhibitory peptides [3]. Research has shown that ACE inhibitory peptides generally consist of hydrophobic amino acid residues at the $\mathrm{C}$ - and/or $\mathrm{N}$ - terminus, and these peptides contain amino acid residues with hydrophobic side chains [4,5]. The bioactive peptides from corn gluten meal obtained by enzymatic hydrolysis have been shown to possess ACE inhibitory properties [6,7]. The enzymes commonly used in the preparation of ACE inhibitory peptides are endopeptidases, such as Alcalase and Neutrase. These endopeptidases release peptides by cleaving 
hydrophobic amino acid peptide bonds in the protein chain, resulting in the N- and / or Cterminus of the ACE inhibitory peptides containing hydrophobic amino acid residues (i.e., Leu, Ile, Val, Tyr, Phe, and Trp) [8]. These hydrophobic amino acid residues are related to the bitterness of the ACE inhibitory peptides [9]. In the literature, the contribution of hydrophobic amino acid residues at the $\mathrm{N}$ - and/or C-terminus to the bitterness can be evident, probably owing to their binding to the human taste G-protein coupled receptors followed by the activation of associated organoleptic signaling processes [10]. Therefore, these ACE inhibitory peptides always have a pronounced bitter taste [11-13], which impedes their acceptance by consumers and limits their utilization in the food industry. Exopeptidases, such as pancreatin, cleave peptide bonds at the terminus of peptides. Hence, in the latter stage, the removal of hydrophobic amino acids at the $\mathrm{N}$ - or $\mathrm{C}$-terminus with exopeptidases can reduce the bitterness. Most of the previous research has focused on the ACE inhibitory activity of peptides. However, systematic research on both ACE inhibitory activity and the bitterness of peptides is unavailable.

To tackle bitterness during the production of ACE inhibitory peptides, diverse debittered methods have been developed, including selective separation of bitter peptides [14], embedding [15], enzymatic debittering [16], and the Maillard reaction [17]. Among them, debittering driven by enzymatic hydrolysis is a process utilizing widely used exopeptidases, or a combination of endopeptidases and exopeptidases. Li and colleagues [18] reported that the debittering effect of the combined use of endo- and exopeptidases was better than the single use of exopeptidases for soy peptides, which was due to the production of more hydrophilic amino acid residues at the C-terminus with endopeptidases. Furthermore, exopeptidases can remove the hydrophobic amino acids related to bitterness at the $\mathrm{N}$ - or C-terminus of peptides. Thus, the resultant hydrolysates tend to exhibit less bitterness and maintain amino acid composition as much as possible. Nevertheless, it is worthwhile to note that, in some cases, the use of the additional exopeptidases may result in the cleavage of key amino acid residues relevant to peptides with bioactive potential, compromising their bioactivity and functional properties [19].

In recent decades, physical processing methods, typically ultrasound, have been reported to enable more active sites of the enzyme to be exposed, resulting from the altered structure of the protein and hydration process. Ultrasound pretreatment could transform the hydrophobic enzyme restriction sites from the inside to the outside [20,21], affecting the cleavage sequence of enzyme restriction sites, which can lead to peptides with more hydrophobic amino acid residues at the $\mathrm{N}$ - or $\mathrm{C}$-terminus. It is then possible to further debitter, via the cleavage of the hydrophobic amino acid residues at the $\mathrm{N}$ - or C-terminus of peptides by exopeptidases. If the side chain of amino acid residues had a highly hydrophobic amino acid, it may have been important in enhancing the activity of the peptides. Bryan and colleagues reported that peptides with a hydrophilic moiety in the side chain exhibited greatly diminished biological activity, whereas those with hydrophobic side chains enhanced growth inhibition activity [22]. However, to date, there is no information about the preparation of ACE inhibitory peptides with low bitterness via an ultrasound-assisted multi-enzymatic system.

Therefore, the objectives of the present study were to investigate the effects of the ultrasound-assisted multi-enzymatic system on bitterness and ACE inhibitory activity of corn gluten meal hydrolysates (CGMHs). First, the multi-enzymatic system was optimized by analyzing the bitterness and ACE inhibitory activity of CGMHs obtained by hydrolysis using different proteases including endopeptidases, exopeptidases, and proteases of a complex type. Furthermore, the effects of energy-gathered ultrasound and divergent ultrasound pretreatments on the hydrolysis of corn gluten meal under the optimum multienzymatic system were comparatively studied with extrusion expansion. Finally, the possible debittering mechanism driven by the combined ultrasound pretreatments and enzymolysis of corn gluten meal was unraveled. The key finding of this study is expected to provide a good reference for the development of corn-derived peptides in the food industry. 


\section{Materials and Methods}

\subsection{Materials}

Corn gluten meal (protein content of $60.21 \%$ ) was provided by Shandong Tiancheng Biotechnology Co., Ltd. (Shandong, China); Alcalase $\left(3.59 \times 10^{5} \mathrm{U} / \mathrm{g}\right)$, Neutrase $\left(4.90 \times 10^{5} \mathrm{U} / \mathrm{g}\right)$, Flavourzyme $\left(1.62 \times 10^{5} \mathrm{U} / \mathrm{g}\right)$, papain $\left(3.25 \times 10^{4} \mathrm{U} / \mathrm{g}\right)$, trypsin $\left(1.64 \times 10^{5} \mathrm{U} / \mathrm{g}\right)$, and pancreatin $\left(3.80 \times 10^{5} \mathrm{U} / \mathrm{g}\right)$ were purchased from Pang Bo Bioengineering Co., Ltd. (Shanghai, China); Protamex (activity of $1.03 \times 10^{5} \mathrm{U} / \mathrm{g}$ ) was purchased from Henan Baichuang Biotechnology Co., Ltd. (Qi Hebi, China); ANS (1-Anilino-8-naphthalenesulfonic acid) and FAPGG (N-[3-(2-Furyl)acryloyl]-Phe-Gly-Gly) were purchased from Sigma-Aldrich Corp (Burlington, MA, USA). All other chemicals and solvents used in the experiment were of analytical grade.

\subsection{Energy-Gathered Ultrasound Pretreatment}

In an ultrasound processor (Shangjia Biotechnology Co., Wuxi, China; Model GA92II DB), $2000 \mathrm{~mL}$ of sample suspensions were sonicated with a $2.0 \mathrm{~cm}$ immersion of the ultrasonic probe as shown in Figure 1b. The process of energy-gathered ultrasound was monitored under the conditions set at an ultrasound on-time of $3 \mathrm{~s}$, ultrasound off-time of $3 \mathrm{~s}$, total working time of $30 \mathrm{~min}$, ultrasonic power of $300 \mathrm{~W}$, and the initial temperature of $25{ }^{\circ} \mathrm{C}$. Specifically, the sample suspensions were stirred and preheated at $25^{\circ} \mathrm{C}$ using a water bath for $30 \mathrm{~min}$, and then subjected to energy-gathered ultrasound pretreatment.
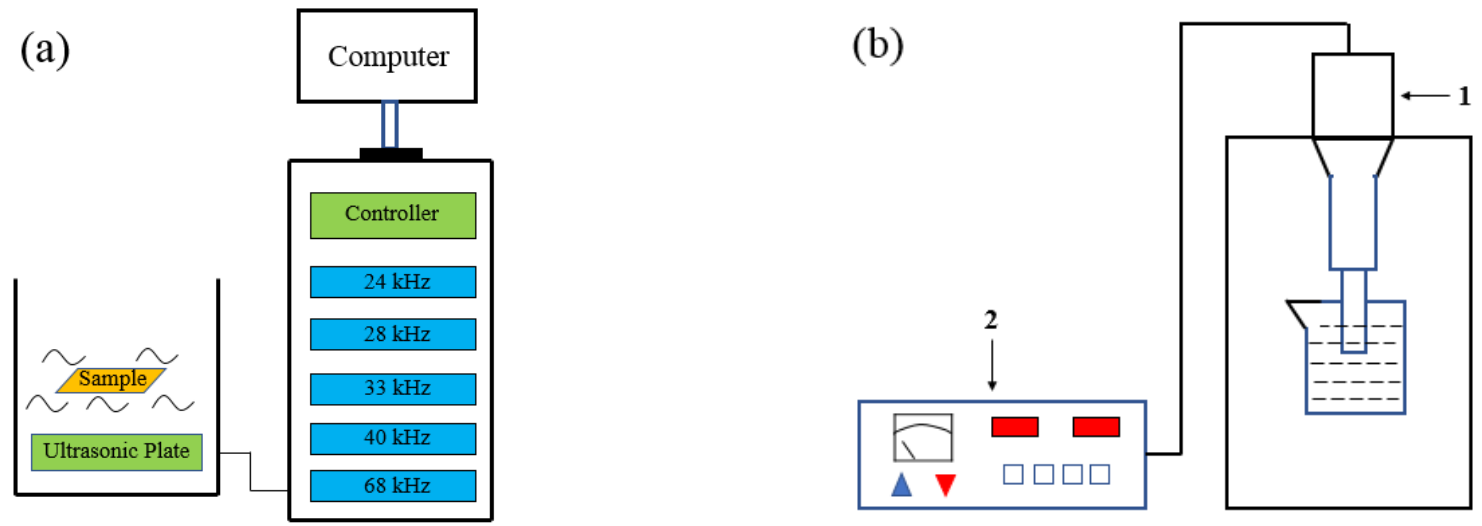

(c)

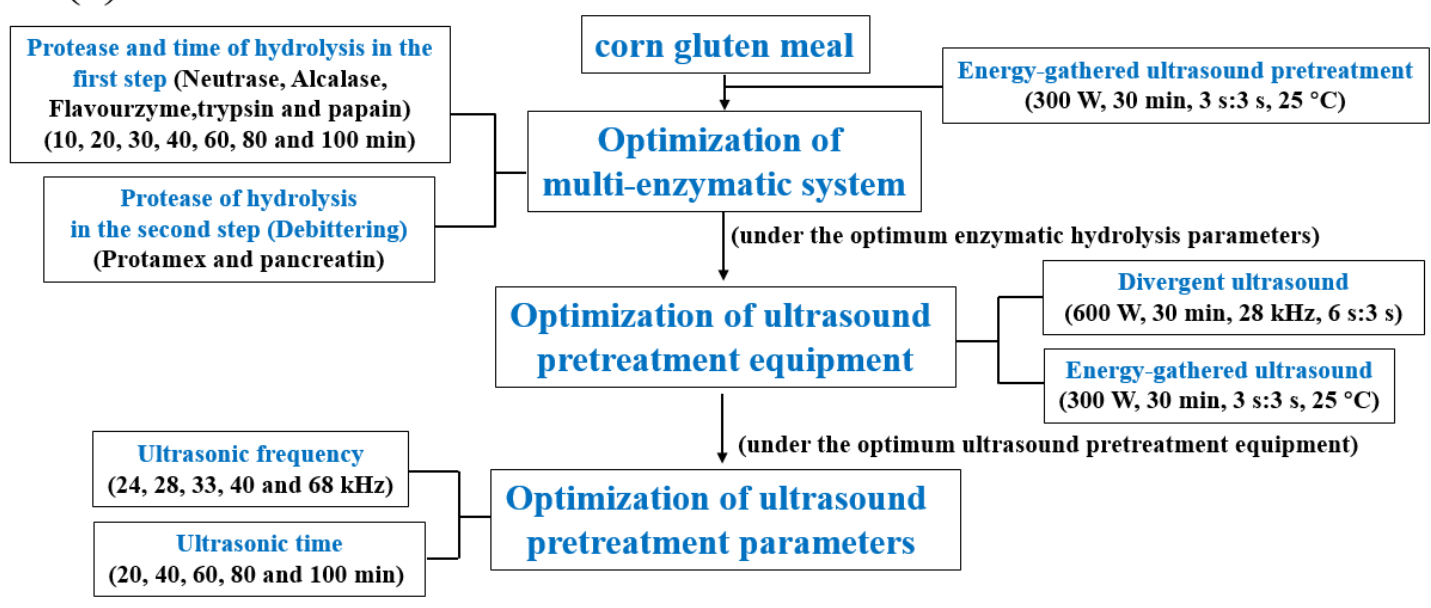

Figure 1. (a) Diagram of the divergent ultrasound equipment; (b) Diagram of the energy-gathered ultrasound equipment. 1: Ultrasonic probe; 2: Ultrasonic controller; (c) Experimental flow chart. 


\subsection{Optimization of Enzymatic Hydrolysis Parameters}

In this study, the hydrolysis of corn gluten meal pretreated by energy-gathered ultrasound was divided into two steps.

In first-step hydrolysis, $27 \mathrm{~g}$ of corn gluten meal was dispersed in $400 \mathrm{~mL}$ of deionized water and mixed for $5 \mathrm{~min}$. The suspension was then preheated at the optimum temperature for the proteases using a water bath for $10 \mathrm{~min}$, and the $\mathrm{pH}$ was adjusted to the optimum $\mathrm{pH}$ for the selected protease with $1 \mathrm{M} \mathrm{NaOH}$. The optimal temperature and $\mathrm{pH}$ conditions of each protease were set as follows: Flavourzyme $\left(50{ }^{\circ} \mathrm{C}, \mathrm{pH} 7.0\right)$, Alcalase $\left(50{ }^{\circ} \mathrm{C}, \mathrm{pH}\right.$ 8.0), Neutrase $\left(50^{\circ} \mathrm{C}, \mathrm{pH} 7.0\right)$, papain $\left(55^{\circ} \mathrm{C}, \mathrm{pH} 7.0\right)$, and trypsin $\left(40^{\circ} \mathrm{C}, \mathrm{pH} 7.5\right)$ [23]. For each of the selected proteases, a dose of $800 \mathrm{mg}$ was added to initiate the enzymatic reaction for different enzymolysis times $(10,20,30,40,60,80$, and $100 \mathrm{~min})$, before the reaction was terminated using a boiling water bath for $10 \mathrm{~min}$ to inactivate the proteases. Meanwhile, the $\mathrm{pH}$ was stabilized by continuously titrating with a $1 \mathrm{M} \mathrm{NaOH}$ solution and the temperature was held constant by using a thermostat water bath (HH-6, Jintan Fuhua Instrument Factory, Jiangsu, China).

In second-step hydrolysis, as soon as the hydrolysates were cooled down to room temperature, they were adjusted to the optimum temperature and $\mathrm{pH}$ of the selected exopeptidase. The optimal temperature and $\mathrm{pH}$ conditions of each exopeptidase were set as follows: pancreatin $\left(37^{\circ} \mathrm{C}, \mathrm{pH} 8.0\right)$ and Protamex $\left(50^{\circ} \mathrm{C}, \mathrm{pH} 7.0\right)$. Protamex and pancreatin are common debittering proteases [24]. Afterwards, a dose of 5\% [E/S] of the selected exopeptidase was added to the hydrolysates obtained in the first-step hydrolysis, followed by a water bath for enzymolysis for a fixed time of $30 \mathrm{~min}$. Meanwhile, the temperature was set to the optimum temperature for the selected exopeptidase. The reaction was terminated using a boiling water bath for $10 \mathrm{~min}$ to inactivate the exopeptidase. Finally, the suspension was cooled down to room temperature and the $\mathrm{pH}$ was adjusted to 7.0. Then, the suspension was centrifuged at 12,000 $\mathrm{r} / \mathrm{min}$ for $5 \mathrm{~min}$. The resulting supernatant was used to determine the ACE inhibitory activity and bitterness for the optimization of enzyme and hydrolysis time. Corn gluten meal suspension without enzymolysis was set as the control.

\subsection{Optimization of Ultrasound Pretreatment Equipment}

Corn gluten meal was pretreated with two different kinds of ultrasound pretreatments (divergent ultrasound and energy-gathered ultrasound). Corn gluten meal suspensions were hydrolyzed under the optimum enzymatic hydrolysis parameters. The ACE inhibitory activity and the bitterness intensity were set as variables for the optimization of the ultrasound pretreatment. Corn gluten meal suspension without ultrasound pretreatment was set as the control.

\subsubsection{Divergent Ultrasound}

Sample suspensions were conducted in an ultrasonic bath reactor developed by our research group, shown in Figure 1a, equipped with five different frequencies $(24,28,33,40$, and $68 \mathrm{kHz}$ ). Each ultrasonic generator had a total power of $600 \mathrm{~W}$. The whole ultrasonic radiation volume was $4000 \mathrm{~mL}$, including $3600 \mathrm{~mL}$ of distilled water and $400 \mathrm{~mL}$ of the corn gluten meal suspensions. The process of divergent ultrasound was monitored under conditions set at an ultrasonic frequency of $28 \mathrm{kHz}$, ultrasonic power of $600 \mathrm{~W}$, ultrasonic time of $30 \mathrm{~min}$, and ultrasonic pulse on- and off- time of 6 and $3 \mathrm{~s}$, respectively.

\subsubsection{Energy-Gathered Ultrasound}

The method of energy-gathered ultrasound pretreatment of corn gluten meal suspension was according to Section 2.2.

\subsubsection{Positive Control}

Corn gluten meal suspension with extrusion expansion pretreatment was set as the positive control. Briefly, corn gluten meal (added with 30\% water) was pretreated with a 
twin-screw extrusion cooker (Brabender Technology Co., Duisburg, Germany; DSE 20/400). The extrusion expansion process was monitored at the following temperatures: I-zone temperature of $85^{\circ} \mathrm{C}$, II-zone temperature of $110^{\circ} \mathrm{C}$, and III-zone temperature of $120^{\circ} \mathrm{C}$. The corn gluten meal was dried at a temperature of $105^{\circ} \mathrm{C}$ to a constant weight. After drying, $24.57 \mathrm{~g}$ of this extruded corn gluten meal (deducted its initial moisture 9\%) was dispersed in $400 \mathrm{~mL}$ of deionized water and mixed for $5 \mathrm{~min}$.

\subsection{Optimization of Ultrasound Pretreatment Parameters}

To optimize the ultrasound pretreatment parameters, $27 \mathrm{~g}$ of corn gluten meal was dispersed in $400 \mathrm{~mL}$ of deionized water and mixed for $5 \mathrm{~min}$. Sample suspensions were pretreated with ultrasound pretreatment. The divergent ultrasound pretreatment was conducted under the following conditions: ultrasonic time for $30 \mathrm{~min}$ and ultrasonic frequencies of 24, 28, 33, 40, and $68 \mathrm{kHz}$; under the optimized ultrasonic frequency and ultrasonic times for 20, 40, 60, 80, and $100 \mathrm{~min}$. The ACE inhibitory activity and the bitterness were set as variables for the optimization of ultrasound pretreatment parameters. The flow chart of the optimization test is shown in Figure 1c, including the optimization of enzymatic hydrolysis parameters, ultrasound pretreatment equipment, and ultrasound pretreatment parameters.

\subsection{Determination of the Degree of Hydrolysis (DH)}

The $\mathrm{pH}$-stat method was chosen according to Adler-Nissen [25] to determinate DH (\%) using the following equations:

$$
\begin{gathered}
\alpha=\frac{10^{p H-p K}}{1+10^{p H-p K}} \\
\mathrm{DH}(\%)=\frac{N_{b} \times B \times 100}{\alpha \times M_{p} \times h_{t o t}}
\end{gathered}
$$

where $B$ is the $\mathrm{NaOH}$ solution volume being consumed, $\mathrm{mL} ; N_{b}$ is the concentration of $\mathrm{NaOH}$ solution, $\mathrm{M} ; \alpha$ is the average dissociation degree of $\alpha-\mathrm{NH}_{2}$ in the substrate, influenced by the particular temperature and $\mathrm{pH}$ of hydrolysis, which is calculated according to Equation (1); $M_{p}$ is the mass of the hydrolyzed protein, $g ; h_{t o t}$ is the mole number of peptide bonds per quality of protein, which is $9.2 \mathrm{mmol} / \mathrm{g}$ for corn gluten meal.

\subsection{Determination of ACE Inhibitory Activity}

The ACE inhibitory activity was determined according to the method of ActisGoretta [26] with some modifications. The sample was diluted 50-fold using distilled water. In a $37^{\circ} \mathrm{C}$ incubator (BXP-6, Lichen Technology Co., Ltd., Shanghai, China), $100 \mu \mathrm{L}$ of the sample dilution and $50 \mu \mathrm{L}$ of ACE was mixed with $50 \mu \mathrm{L}$ of $1.0 \mathrm{mM}$ FAPGG, dissolved in $0.08 \mathrm{M}$ HEPES buffer containing $0.3 \mathrm{M} \mathrm{NaCl}(\mathrm{pH} 8.3$ ) for $30 \mathrm{~min}$. Then the absorbance difference of the sample before and after the reaction was measured at $340 \mathrm{~nm}$ with a multi-wavelength microplate reader (Tecan Infinite PRO TWIN 200, Tecan Co., Ltd., Zürich, Switzerland) and recorded as $b_{1}$ and $b_{2}$. The blank was prepared according to the above method, but the sample dilution was replaced by the same volume of $0.08 \mathrm{M}$ HEPES buffer. The absorbance difference of the blank was also measured and recorded as $a_{1}$ and $a_{2}$. The ACE inhibitory activity (\%) was calculated according to the equation:

$$
\text { ACE inhibitory rate }(\%)=\frac{\left(a_{1}-a_{2}\right)-\left(b_{1}-b_{2}\right)}{a_{1}-a_{2}} \times 100
$$

\subsection{Sensory Evaluation of Bitterness}

Following the methodology provided by Minagawa and colleagues [27], a sensory evaluation of the bitter taste in hydrolysates was implemented by panelists (4 females and 4 males, aged between 25 and 30). The standard solution is based on the concentration of 
quinine, and $\mathrm{E}\left(\mathrm{E}=8 \times 10^{-8} \mathrm{~mol} / \mathrm{L}\right)$ is the minimum value. At each sensory evaluation, panelists were presented with solutions of $\mathrm{E}, 5 \mathrm{E}, 50 \mathrm{E}, 500 \mathrm{E}$, and $1250 \mathrm{E}$ of quinine, which had been labeled as $0,1,2,3$, and 4 on the bitter scale ( 0 , no bitterness; 1 , weakly bitter; 2 , bitter; 3, strongly bitter; and 4, extremely bitter). The solution of $E$ of quinine was used as the standard for no bitterness. Panelists then evaluated the bitterness scores of the assayed samples in a randomized order on the basis of the quinine standards they had tasted and panelists were asked to rinse their mouths entirely with double distilled water between tasting the hydrolysate samples.

\subsection{Characterization by Intrinsic Fluorescence Spectra}

The intrinsic fluorescence emission spectra of corn gluten meal $(0.4 \mathrm{mg} / \mathrm{mL}, w / v)$ samples were profiled at room temperature $\left(25 \pm 1^{\circ} \mathrm{C}\right)$ with a fluorescence spectrophotometer (Model Cary Eclipse, Varian Inc., Palo Alto, CA, USA). An excitation wavelength of $280 \mathrm{~nm}$ (slit $10.0 \mathrm{~nm}$ ), emission wavelength range of $320-520 \mathrm{~nm}$ (slit $5.0 \mathrm{~nm}$ ), and scanning speed of $120 \mathrm{~nm} / \mathrm{min}$ were set.

\subsection{Hydrophobic Amino Acid Composition Analysis}

The amino acid composition was determined using an automatic amino acid analyzer (S433D, Saikam Scientific Instruments Co., Ltd., Leipzig, Germany) according to the method described by Zhang and colleagues [28] with some modifications. A $100 \mathrm{mg}$ sample was hydrolyzed in $10 \mathrm{~mL}$ of $6 \mathrm{M} \mathrm{HCl}\left(110^{\circ} \mathrm{C}, 24 \mathrm{~h}\right)$. The hydrolysates were then cooled and dried in a vacuum desiccator at $45^{\circ} \mathrm{C}$, and the amino acid composition was determined.

\subsection{Measurement of Molecular Weight Distribution of Hydrolysates}

TOSOH Bioscience, LLC provided a TSK gel G2000 SWXL $300 \mathrm{~mm} \times 7.8 \mathrm{~mm}$ (flow rate of $0.5 \mathrm{~mL} / \mathrm{min}$, sample injection of $20 \mu \mathrm{L}$, column temperature of $30^{\circ} \mathrm{C}$ ) for the analysis of the molecular weight distribution of the hydrolysates. The mobile phase $(0.02 \mathrm{M}$ phosphate buffer having $0.25 \mathrm{M} \mathrm{NaCl}, \mathrm{pH} 7.2$ ) eluted at a flow rate of $0.5 \mathrm{~mL} / \mathrm{min}$. A molecular weight calibration curve was prepared from the average elution volume of the standards: bacitracin (1422 Da), Gly-Gly-Tyr-Arg (451.2 Da), and Glycyl-Glycyl-Glycine (189.1 Da). (Sigma Co., Burlington, MA, USA). UNICORN 5.0 software (Amersham Biosciences Co., Piscataway, NJ, USA) was used to analyze the chromatographic data.

\subsection{Statistical Analysis}

The analysis of results was performed using an ANOVA under a significance level of $p<0.05$ with SPSS 13.0 software (IBM Corporation, New York, NY, USA) and the significant differences between means were detected by an LSD test. All graphs were created using OriginPro8.0 (Origin Lab Corporation, Northampton, MA, USA). All data are presented as means with standard errors $(n=3)$.

\section{Results and Discussion}

\subsection{ACE Inhibitory Activity of CGMHs}

Figure 2a shows the effects of hydrolysis time on ACE inhibitory activity of CGMHs prepared using five different commercial proteases (Neutrase, Alcalase, Flavourzyme, trypsin, and papain) combined with Protamex. The chosen protease and hydrolysis time had significant effects on the ACE inhibitory activity of the CGMHs, as different proteases and hydrolysis times can produce different types of peptides $[29,30]$. Notably, the ACE inhibitory activity of the CGMHs produced from Neutrase-Protamex (NP) sequential enzymolysis varied from $19.29 \%$ to $88.51 \%$, and the highest ACE inhibitory activity value, at $88.51 \%$, was obtained after $40 \mathrm{~min}$ of Neutrase hydrolysis. The CGMHs obtained by Alcalase-Protamex (AP) sequential enzymolysis had various ACE inhibitory activity ranging from $40.89 \%$ to $69.37 \%$. The ACE inhibitory activity of CGMHs achieved using Flavourzyme-Protamex (FP) sequential enzymolysis was in the range of $19.87 \%$ to $40.44 \%$, and the highest ACE inhibitory activity value, at $40.44 \%$, was achieved after $20 \mathrm{~min}$ of 
Flavourzyme hydrolysis. Among five kinds of sequential enzymolysis, NP was the highest, followed by AP, FP, papain-Protamex (PP), and trypsin-Protamex (TP). CGMHs produced by FP showed high ACE inhibitory activity, which was similar to the results of Suh and colleagues [31], who found that hydrolysates prepared from corn gluten by Flavourzyme showed high ACE inhibitory activity ( $\mathrm{IC}_{50}: 0.18 \mathrm{mg}$ solid). Flavourzyme is a complextype (endo- and exo-type) enzyme and is recommended for the production of debittered hydrolysates. Regarding debittered hydrolysates, Protamax produces a lower amount of Glu, and higher Leu and Ile, resulting in the bitter taste [31]. Ko and colleagues [32] reported that among the nine proteases Protamex, Kojizyme, Neutrase, Flavourzyme, Alcalase, pepsin, trypsin, $\alpha$-chymotrypsin, and papain, Protamex hydrolysates of flesh tissue possessed the highest ACE inhibitory activity. The possible mechanism was that Protamex could release potent ACE inhibitory peptides from debittered hydrolysates by Flavourzyme [33].
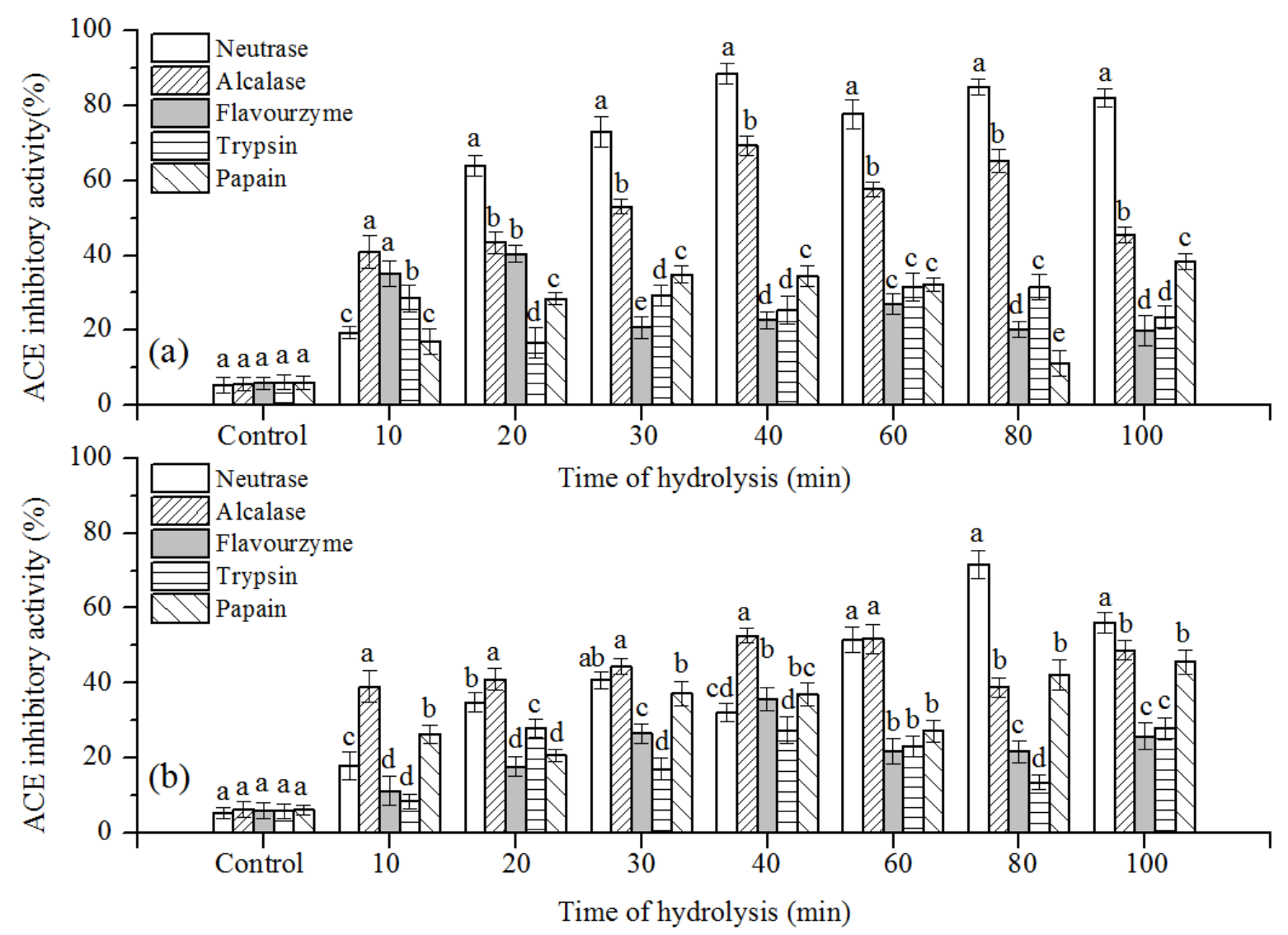

Figure 2. (a) Effect of hydrolysis time on the ACE inhibitory activity of CGMHs using different proteases in combination with Protamex; (b) Effects of hydrolysis time on the ACE inhibitory activity of CGMHs using different proteases in combination with pancreatin. Significant differences between results are indicated by different letters $(p<0.05)$.

The effect of hydrolysis time on the ACE inhibitory activity of CGMHs produced by five different commercial proteases in combination with pancreatin are shown in Figure 2b. The ACE inhibitory activities owing to the hydrolysis of five different proteases (Neutrase, Alcalase, Flavourzyme, trypsin, and papain) combined with pancreatin varied, ranging from $8.40 \%$ to $71.67 \%$. Among the five kinds of sequential enzymolysis, it was clear that the Neutrase-pancreatin (NPa) sequential enzymolysis obtained the highest ACE inhibitory activity with a value of $71.67 \%$ after $80 \mathrm{~min}$ of Neutrase hydrolysis. The second highest ACE inhibitory activity $(52.66 \%)$ was produced by Alcalase-pancreatin (APa) sequential enzymolysis after $40 \mathrm{~min}$ of Alcalase hydrolysis. As a whole, the ACE inhibitory activity of CGMHs prepared using five different commercial proteases combined with Protamex 
was higher than that combined with pancreatin. This can be explained by the fact that Protamex was beneficial to the preparation of high ACE inhibitory peptides [34]. Another possible reason might be that pancreatin had higher exo-peptidase activity than Protamex, and thus pancreatin could cleave more hydrophobic amino acid residues exposed at the Nor C-terminus [35].

\subsection{Evaluation of the Bitterness Sensation and Intensity of CGMHs}

Figure 3a shows the effects of hydrolysis time on the bitterness intensity of CGMHs prepared by five different proteases in combination with Protamex. Among the five kinds of sequential enzymolysis, AP sequential enzymolysis obtained the highest bitterness intensity with the value of 3.75 after $20 \mathrm{~min}$ of Alcalase hydrolysis. The second highest bitterness intensity (3.30) was derived by the treatment of NP sequential enzymolysis after 40 min of Neutrase hydrolysis. FP sequential enzymolysis showed the lowest bitterness intensity (2.39) after 20 min of Flavourzyme hydrolysis. It was not surprising that Alcalase and Neutrase had the tendency to hydrolyze at hydrophobic amino acid residue positions. It was reported that peptides with hydrophobic amino acid residues at the C-terminal had high bitterness [36]. Fu and colleagues [37] reported that hydrolysates of bovine muscle and porcine plasma produced by Flavourzyme elicited low bitterness. The difference in bitterness of CGMHs indicated the presence of multiple cleavage sites on peptides that were acted upon by proteases of various origins and types. After all, Flavourzyme has not only endo-peptidase activity, but also exo-peptidase activity compared to Alcalase or Neutrase.
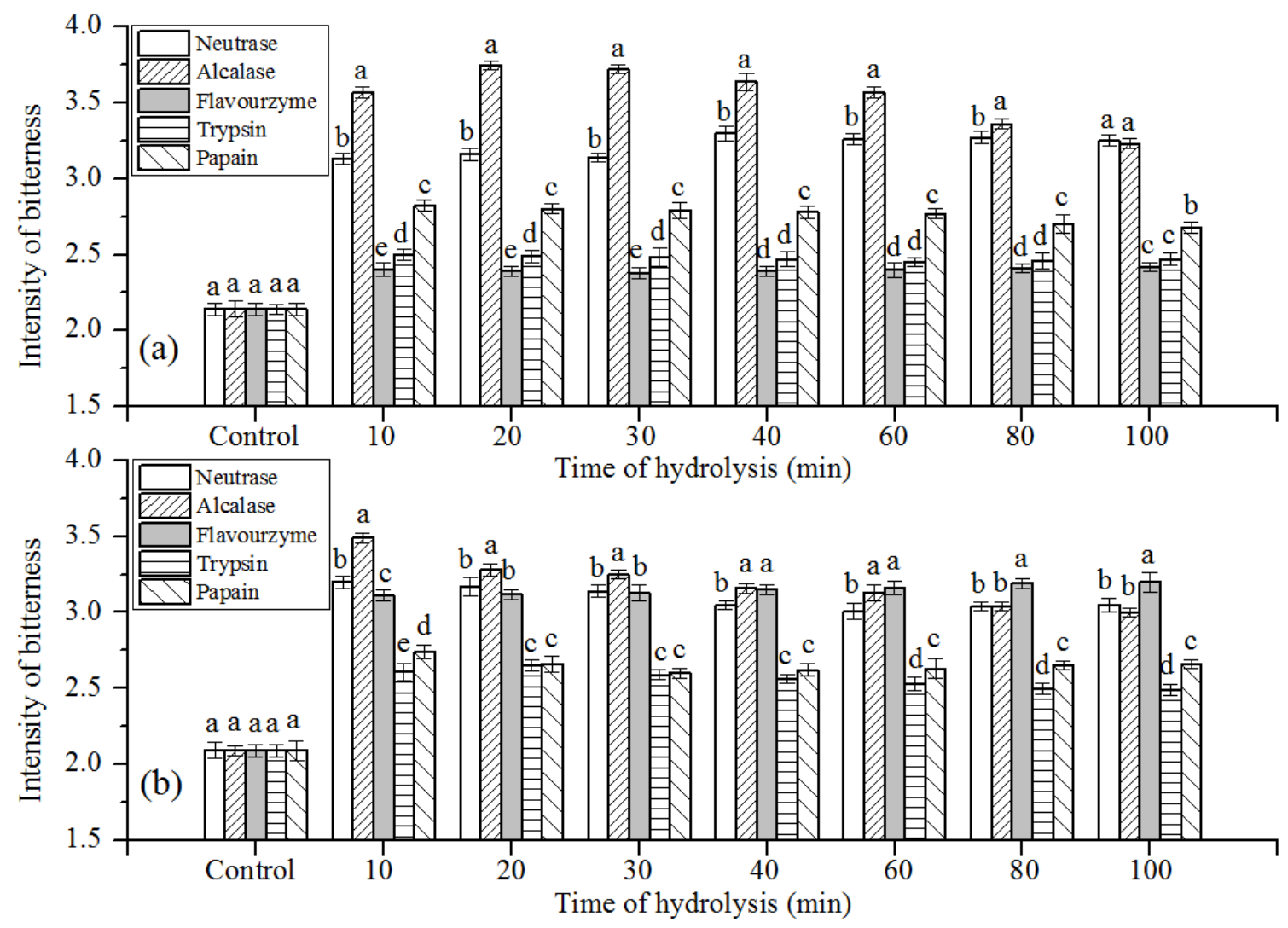

Figure 3. (a) Effect of hydrolysis on the bitterness intensity of CGMHs using different proteases in combination with Protamex; (b) Effects of hydrolysis on the bitterness intensity of CGMHs using different proteases in combination with pancreatin. Significant differences between results are indicated by different letters $(p<0.05)$.

The effects of hydrolysis time on the bitterness intensity of CGMHs produced by five different proteases in combination with pancreatin are illustrated in Figure $3 b$. The 
results show that $\mathrm{APa}$ sequential enzymolysis obtained the highest bitterness intensity (3.49) after 10 min of Alcalase hydrolysis, followed by hydrolysates produced from $\mathrm{NPa}$ sequential enzymolysis after 80 min of Neutrase hydrolysis (with the value of 3.04). The CGMHs obtained by Flavourzyme-pancreatin (FPa) sequential enzymolysis had various bitterness intensities ranging from 3.11 to 3.19. The trypsin-pancreatin (TPa) sequential enzymolysis showed the lowest bitterness intensity with a range of 2.49 to 2.65 . As a whole, the bitterness intensity of CGMHs prepared using five different commercial proteases combined with Protamex, was higher than that combined with pancreatin, except for FP and TP sequential enzymolysis. This indicated that the ACE inhibitory activity of CGMHs was not all positively correlated with bitterness intensity. These findings were consistent with those of $\mathrm{Wu}$ and colleagues [38], who discovered no significant relationship between ACE inhibitory activity and bitterness intensity in di- and tri-peptides. Pripp and colleagues [12] found that the relationship between peptide bitterness intensity and ACE inhibitory activity was weaker for oligopeptides than dipeptides.

The bitterness sensation of the CGMHs prepared by TP, TPa, and FP sequential enzymolysis were generally acceptable to the panelists. Among these three enzymatic combinations, the ACE inhibitory activity of the CGMHs produced by FP was highest with the value of $40.44 \%$. Based on the integrated consideration of ACE inhibitory activity and bitterness intensity, CGMHs produced by FP sequential enzymolysis were favorable for the preparation of ACE inhibitory peptides with low bitterness. Therefore, FP sequential enzymolysis was the optimum multi-enzymatic hydrolysis preparation of corn gluten meal.

\subsection{Effects of Ultrasound Pretreatment on the Enzymolysis of Corn Gluten Meal}

Figure 4 shows the effects of divergent ultrasound pretreatment on ACE inhibitory activity and bitterness intensity of CGMHs under optimum multi-enzymatic hydrolysis parameters. In the multi-enzymatic system, divergent ultrasound pretreatment had significant effects on the ACE inhibitory activity and bitterness intensity of CGMHs. The divergent ultrasound pretreatment performance in ACE inhibitory activity (with its value of 55.31\%) did not show any significant difference compared to extrusion expansion pretreatment. In terms of energy consumption and safety, divergent ultrasound pretreatment was superior to extrusion expansion pretreatment. The divergent ultrasound pretreatment in ACE inhibitory activity increased markedly by $20.11 \%$ compared to energy-gathered ultrasound pretreatment with its value of 46.05\%. Similarly, Jin [39] reported that divergent ultrasound pretreatment is more suitable for the enzymolysis of corn gluten meal compared to energy-gathered ultrasound pretreatment. The possible reason was that divergent ultrasound is plate type, the ultrasonic energy distribution in the reaction system is more uniform, and energy-gathered ultrasound only produces instantaneous high temperature, high pressure, and shear force at the tip of the ultrasonic probe [40]. Therefore, for corn gluten meal with strong hydrophobicity, divergent ultrasound pretreatment can prevent the exposed hydrophobic groups from rearrangement.

Regarding bitterness intensity, the divergent ultrasound pretreatment was close to extrusion expansion pretreatment $(p>0.05)$ with the value of 2.26 . The bitterness intensity from the divergent ultrasound pretreatment decreased significantly by $5.8 \%(p<0.05)$ compared to energy-gathered ultrasound pretreatment with a value of 2.40. Thus, the divergent ultrasound pretreatment contributed to the higher ACE inhibitory activity and lower bitterness intensity of the final product compared with energy-gathered ultrasound pretreatment. Considering energy consumption and safety, the divergent ultrasound pretreatment was the optimum pretreatment of corn gluten meal.

\subsection{Effects of Ultrasonic Frequency and Ultrasonic Time on the Enzymolysis of Corn Gluten Meal}

Figure $5 \mathrm{a}, \mathrm{b}$ show the ACE inhibitory activity and bitterness of CGMHs prepared by divergent ultrasound pretreatment at different ultrasonic frequencies $(24-68 \mathrm{kHz})$ and ultrasonic times (20-100 $\mathrm{min})$. 


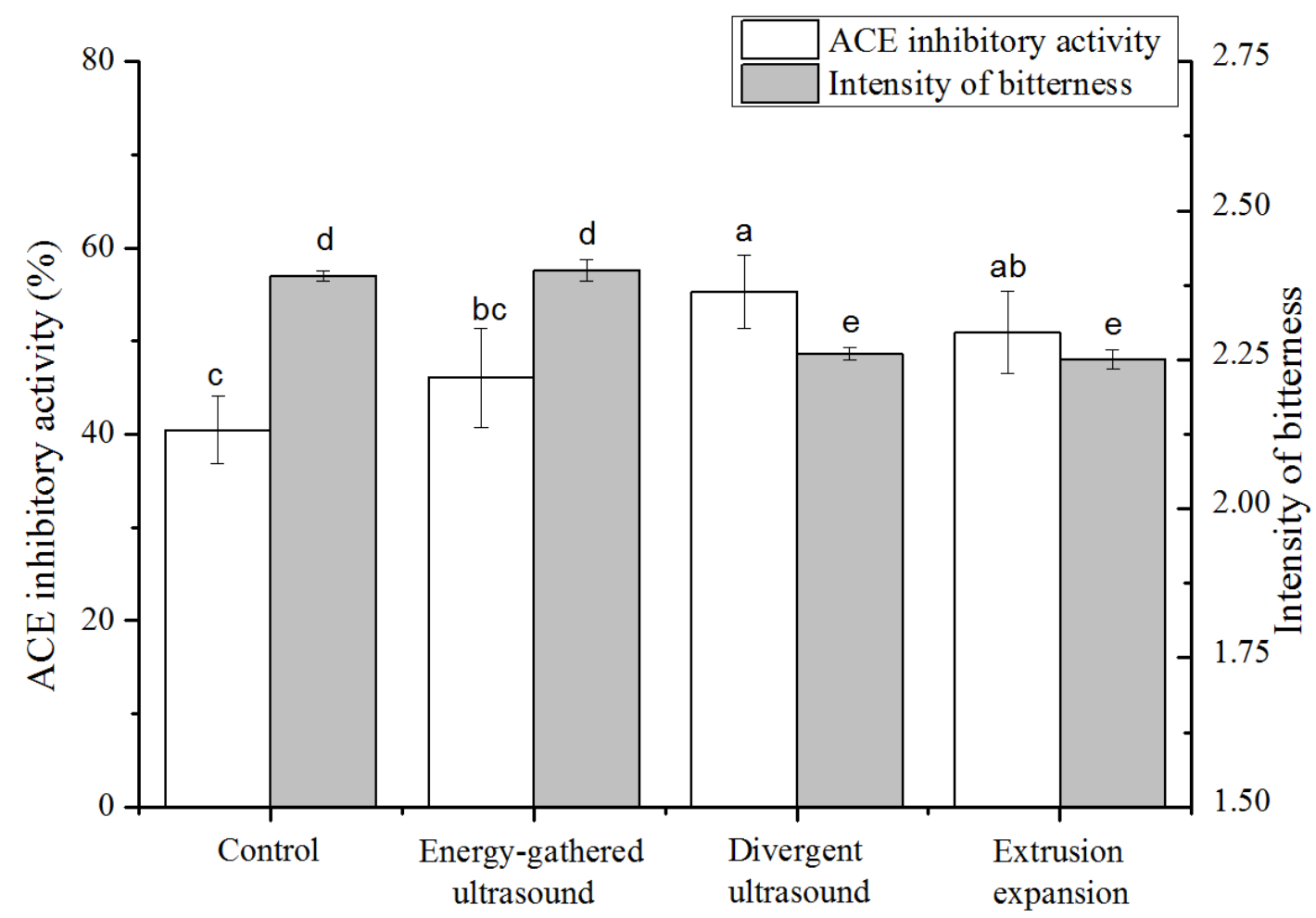

Figure 4. Effect of ultrasound pretreatment on the ACE inhibitory activity and bitterness intensity of CGMHs under optimal multi-enzymatic hydrolysis parameters. Significant differences between results are indicated by different letters $(p<0.05)$.

(a)

(b)

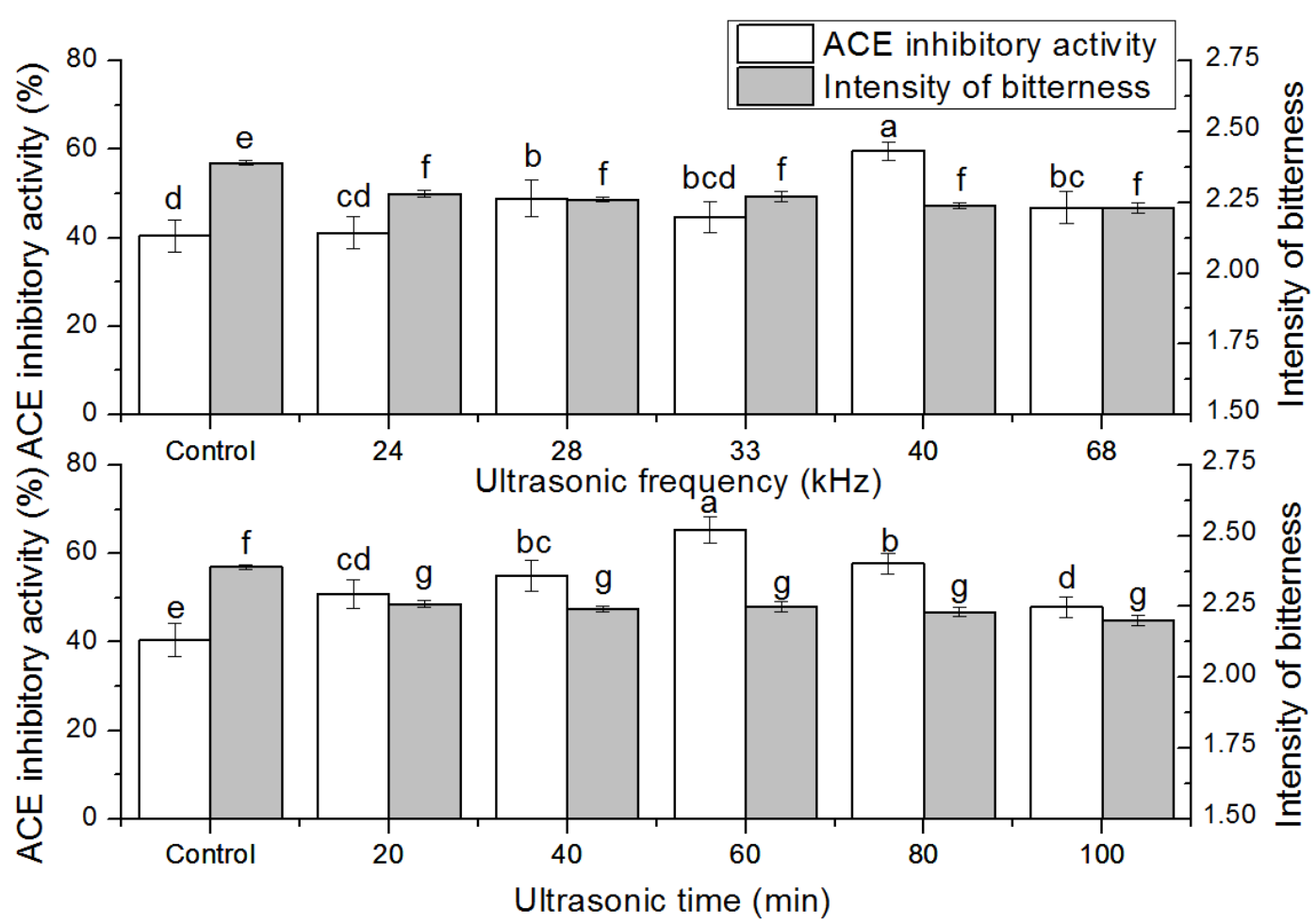

Figure 5. (a) The effect of ultrasonic frequency on the ACE inhibitory activity and bitterness of CGMHs under optimal multi-enzymatic hydrolysis parameters; (b) The effect of ultrasonic time on the ACE inhibitory activity and bitterness of CGMHs under optimal multi-enzymatic hydrolysis parameters. Significant differences between results are indicated by different letters $(p<0.05)$. 
It was clear that the ACE inhibitory activity of CGMHs increased significantly $(p<0.05)$ with an increase in ultrasonic frequency, peaking at $40 \mathrm{kHz}$ (with a value of $59.67 \%$ ), and then gradually dropped with increasing ultrasonic frequency. This finding was in accordance with the result of Yang and colleagues [41], who reported that the ACE inhibitory activity of hydrolysates prepared from the sonicated defatted wheat germ protein at different frequencies increased significantly by $31.94 \%$ compared to the control. The bitterness intensity of CGMHs had no significant difference $(p>0.05)$ with the increase in ultrasonic frequency, which was stabilized at around 2.26. A possible explanation for this may be that the difference in bitterness intensity caused by ultrasonic frequency was offset by the effect of Flavourzyme [42].

Figure $5 \mathrm{~b}$ shows that the bitterness of CGMHs was observed to be stabilized at around 2.26 , showing no significant difference $(p>0.05)$ regardless of the increase in ultrasonic time. Different ultrasonic times had prominent effects on the ACE inhibitory activity of CGMHs. The ACE inhibitory activity of CGMHs reached a maximum $(65.36 \%)$ when ultrasonic time reached up to $60 \mathrm{~min}$ compared with the enzymatic hydrolysis conditions having the highest ACE inhibitory activity (88.51\%); although ACE inhibitory activity accounted for $73.84 \%$ of the highest ACE inhibitory activity, bitterness intensity was decreased by one level from bitter (3.27) to weakly bitter. Therefore, the optimal divergent ultrasound parameters were as follows: an ultrasonic frequency of $40 \mathrm{kHz}$ and ultrasonic time of $60 \mathrm{~min}$.

\subsection{Intrinsic Fluorescence Spectra}

Intrinsic fluorescence spectroscopy has been widely used to sensitively measure the protein conformational changes resulting from the alteration of the polarity microenvironment [43]. The main aromatic amino acids, such as Tyr, Phe, and Trp, exposed to the protein surface could emit intrinsic fluorescence. Figure 6 shows that corn gluten meal samples pretreated by divergent ultrasound have higher fluorescence intensities compared to samples pretreated with either energy-gathered ultrasound or extrusion expansion, though all of the pretreated samples displayed greater fluorescence intensities compared with the control. This indicates that divergent ultrasound pretreatment exposed more hydrophobic amino acids towards the protein surface than other pretreatments. Therefore, the divergent ultrasound pretreatment was beneficial to produce the peptides with more hydrophobic amino acids under the hydrolysis of Flavorzyme. Additionally, those hydrophobic amino acids were not only at the $\mathrm{N}$ - or C-terminus of peptides, but also in the side chain of amino acid residues, so it is possible to further debitter, including favorable cleavage of the hydrophobic amino acid residues at the N- or C-terminal of peptides with hydrolysis using Protamex. Furthermore, more hydrophobic amino acids in the side chains of amino acid residues are beneficial to improving the ACE inhibitory activity of CGMHs. In brief, the divergent ultrasound pretreatment of corn gluten meal might change the protein conformation with an enhanced exposure of hydrophobic amino acids towards the protein surface [44]. Our results indicated that the ultrasound-induced unfolding of the structure of corn gluten meal protein potentially reduced the bitterness intensity of CGMHs. Due to this, the enzyme accessibility to the interior structure of proteins could probably be improved [41]. 


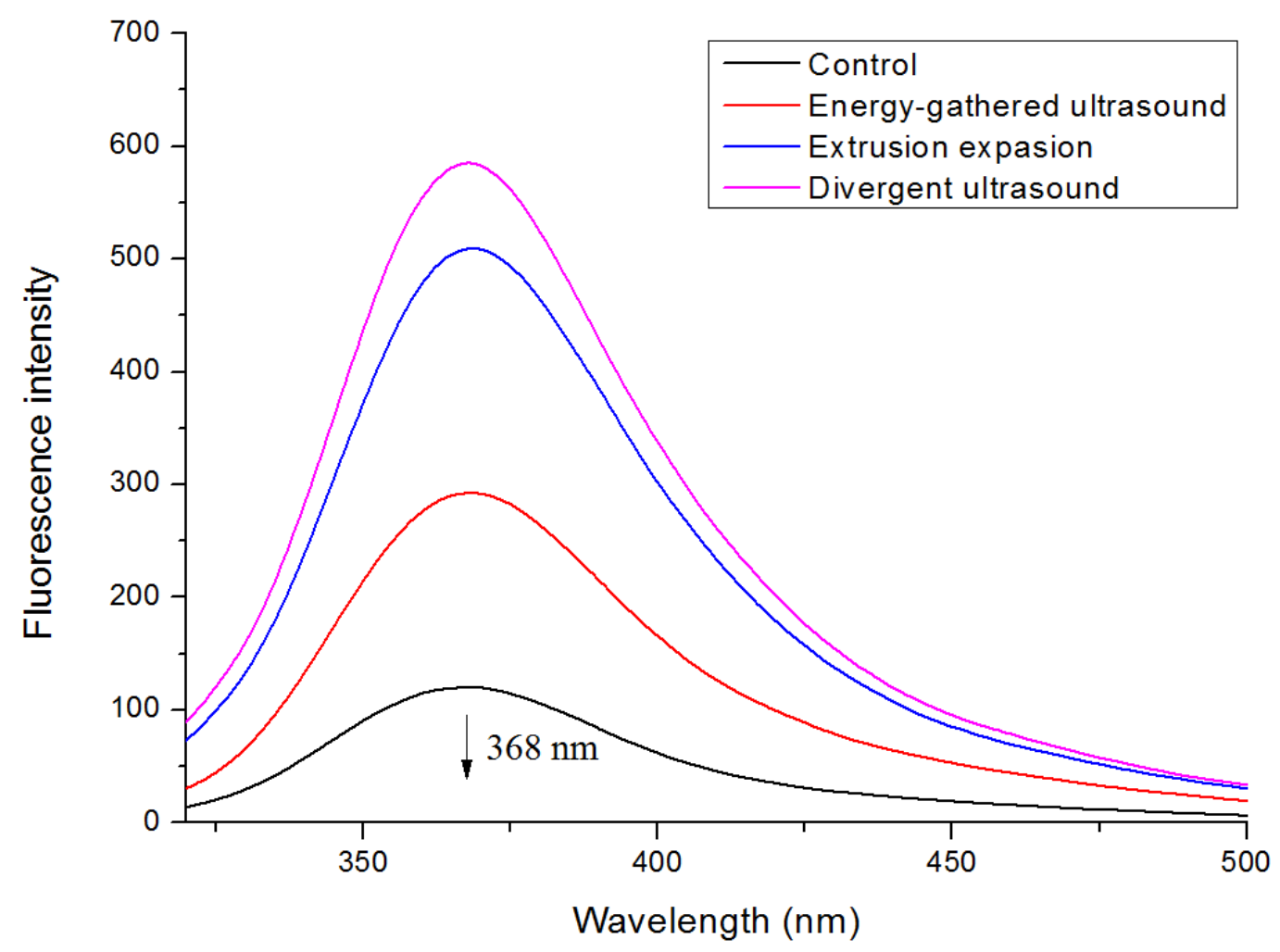

Figure 6. Intrinsic fluorescence emission spectra of proteins subjected to different ultrasound pretreatments.

\subsection{Hydrophobic Amino Acid Composition of CGMHs}

Peptide bitterness is related to hydrophobic amino acid content and molecular weight distribution [37]. The hydrophobic amino acid content of CGMHs with different treatments can be found in Table 1. The optimum conditions were as follows: FP sequential enzymolysis, with a divergent ultrasound pretreatment using an ultrasonic frequency of $40 \mathrm{kHz}$ and an ultrasonic time of $60 \mathrm{~min}$. The results indicated that the total hydrophobic amino acid content of CGMHs under the conditions producing the highest ACE inhibitory activity reached up to $55.7 \%$, which was increased by $5.1 \%(p<0.05)$ compared with that of CGMHs under the optimum conditions. The Leu and Ala content of CGMHs under the conditions producing the highest ACE inhibitory activity was significantly higher than that under the optimum conditions. Ney [45] reported that the bitterness intensity of di-peptides containing Leu was almost twice as strong as that of di-peptides containing other hydrophobic amino acids. Furthermore, the total hydrophobic amino acid content of CGMHs under the optimum conditions was mostly explained by the higher abundance of Tyr, Ile, Val, and Met (Table 1). This was consistent with the study done by Jia and colleagues [3], who reported that the structural characteristics of ACE inhibitory peptides were that their terminal amino acids were enriched in Tyr, Val, Ala, Ile, Leu, Pro, Trp, and Phe. Although both CGMHs produced under the optimum conditions and under the conditions having the highest ACE inhibitory activity had ACE inhibitory peptides, the structural characteristics of peptides prepared under these two conditions were apparently different, which probably altered the bitterness intensity of CGMHs, as confirmed in Figures 2, 3 and 5. 
Table 1. Comparison of hydrophobic amino acid contents $(\%, \mathrm{~m} / \mathrm{m})$ for enzymatic hydrolysates with different bitterness.

\begin{tabular}{ccc}
\hline Name of Amino Acids & $\mathbf{H}_{\mathbf{A}}$ Mass Fraction/\% & $\mathbf{H}_{\mathbf{B}}$ Mass Fraction/\% \\
\hline Pro & $9.0 \pm 0.03^{\mathrm{a}}$ & $8.9 \pm 0.06^{\mathrm{a}}$ \\
Tyr & $5.2 \pm 0.04^{\mathrm{b}}$ & $5.4 \pm 0.09^{\mathrm{a}}$ \\
Phe & $5.6 \pm 0.06^{\mathrm{a}}$ & $5.6 \pm 0.04^{\mathrm{a}}$ \\
Leu & $16.8 \pm 0.07^{\mathrm{a}}$ & $13.6 \pm 0.03^{\mathrm{b}}$ \\
Ile & $4.1 \pm 0.02^{\mathrm{b}}$ & $4.6 \pm 0.01^{\mathrm{a}}$ \\
Val & $4.7 \pm 0.03^{\mathrm{b}}$ & $5.4 \pm 0.02^{\mathrm{a}}$ \\
Ala & $8.0 \pm 0.07^{\mathrm{a}}$ & $6.7 \pm 0.06^{\mathrm{b}}$ \\
Met & $2.3 \pm 0.03^{\mathrm{b}}$ & $2.8 \pm 0.04^{\mathrm{a}}$ \\
Total amino acids & $55.7 \pm 0.04^{\mathrm{a}}$ & $53.0 \pm 0.04^{\mathrm{b}}$ \\
\hline
\end{tabular}

$\mathrm{H}_{\mathrm{A}}$ : Hydrolysate under the conditions having the highest ACE inhibitory activity; $\mathrm{H}_{\mathrm{B}}$ : Hydrolysate under the optimum conditions. Significant differences between results are indicated by different letters $(p<0.05)$.

\subsection{Molecular Weight Distribution of CGMHs}

As shown in Table 2, our results found that the molecular weight distribution of CGMHs prepared under the conditions having the highest ACE inhibitory activity and under the optimum conditions had the highest percentage (57.15\% and $51.09 \%$, respectively) in the 500-1000 Da peptide fraction. However, the percentages of over 1500, 1000-1500, and below $500 \mathrm{Da}$ fraction for those CGMHs were relatively low (Table 2).

Table 2. Comparison of the molecular weight distribution for enzymatic hydrolysates with different bitterness.

\begin{tabular}{ccccc}
\hline $\begin{array}{c}\text { Molecular Weight } \\
\text { (Da) }\end{array}$ & $>\mathbf{1 5 0 0}$ & $\mathbf{1 0 0 0 - 1 5 0 0}$ & $\mathbf{5 0 0 - 1 0 0 0}$ & $<500$ \\
\hline $\mathrm{H}_{\mathrm{A}}$ Proportion (\%) & $9.96 \pm 1.32^{\mathrm{b}}$ & $7.57 \pm 1.89^{\mathrm{b}}$ & $57.15 \pm 1.16^{\mathrm{a}}$ & $25.32 \pm 2.67^{\mathrm{a}}$ \\
$\mathrm{H}_{\mathrm{B}}$ Proportion $(\%)$ & $14.51 \pm 1.19^{\mathrm{a}}$ & $10.94 \pm 2.34^{\mathrm{a}}$ & $51.09 \pm 2.53^{\mathrm{b}}$ & $23.46 \pm 1.58^{\mathrm{a}}$ \\
\hline
\end{tabular}

$\mathrm{H}_{\mathrm{A}}$ : Hydrolysate under the conditions having the highest ACE inhibitory activity; $\mathrm{H}_{\mathrm{B}}$ : Hydrolysate under the optimum conditions. Significant differences between results are indicated by different letters $(p<0.05)$.

Apart from that, compared to those prepared under the optimum conditions, the CGMHs prepared under the conditions having the highest ACE inhibitory activity had a higher percentage of molecular weight in the 500-1000 Da fraction, which was increased by $11.9 \%$ (Table 2). Additionally, under both conditions, the CGMHs had a close percentage of molecular weight of $<500 \mathrm{Da}$, which had no significant difference $(p>0.05)$. However, the CGMHs under the optimum conditions had a higher percentage of molecular weight of $1000-1500 \mathrm{Da}$ and $>1500 \mathrm{Da}$, which increased by $44.5 \%$ and $45.7 \%$, respectively, compared with the cases where the highest ACE inhibitory activity was obtained (Table 2). Hence, those peptides with a molecular weight of $>1000$ Da were probably related to the reduction of bitterness intensity. Our results coincided well with the results of Fu and colleagues [37], who reported that the bitter taste of protein hydrolysates was positively correlated with a peptide fraction of 500-1000 Da.

\section{Conclusions}

The multi-enzymatic system of FP sequential enzymolysis could produce CGMHs with relatively high ACE inhibitory activity and the lowest bitterness compared with other sequential enzymolysis. In the FP sequential enzymolysis reaction, divergent ultrasound pretreatment was superior to energy-gathered ultrasound pretreatment in ACE inhibitory activity and bitterness intensity of CGMHs. In terms of energy consumption and safety, divergent ultrasound pretreatment was better than extrusion expansion pretreatment, though they had no significant difference in ACE inhibitory activity. Following divergent ultrasound pretreatment with a frequency of $40 \mathrm{kHz}$ for $60 \mathrm{~min}$, the ACE inhibitory activity $(65.36 \%)$ accounted for $73.84 \%$ of the highest ACE inhibitory activity, and the 
relative bitterness intensity was decreased from 3.27 to 2.26 . We further proposed that the molecular mechanism of divergent ultrasound pretreatment promotes ACE inhibitory activity of CGMHs and decreases their bitterness. Divergent ultrasound pretreatment resulted in an increase of intrinsic fluorescence intensity, hydrophobic amino acid content of Tyr, Ile, and Val, and more peptides with a molecular weight $>1000 \mathrm{Da}$, but had a decreased content of the hydrophobic amino acid Leu. Overall, the divergent ultrasoundassisted protein multi-enzymatic system should be an effective approach to prepare ACE inhibitory peptides with low bitterness from corn gluten meal.

Author Contributions: Conceptualization and validation, S.H. and Y.L.; methodology, X.Y.; investigation, data curation and writing-original draft preparation, S.H.; writing-review and editing, Y.L., C.L., S.R. and Y.D.; resources, supervision and project administration, Y.L. and H.M.; funding acquisition, Y.L., W.Q. and H.M. All authors have read and agreed to the published version of the manuscript.

Funding: This paper was supported by the National Natural Science Foundation of China [31872892 and 31701538], the Natural Science Foundation of Jiangsu Universities [17KJB550001] and the Advanced Talents Research Fund of Jiangsu University [16JDG049].

Institutional Review Board Statement: Not applicable.

Informed Consent Statement: Not applicable.

Data Availability Statement: Not applicable.

Acknowledgments: The authors greatly appreciated the financial support obtained from the National Natural Science Foundation of China [31872892 and 31701538], the Natural Science Foundation of the Jiangsu Higher Education Institutions of China [17KJB550001] and the Research Foundation for Advanced Talents of Jiangsu University [16JDG049].

Conflicts of Interest: No conflict of interest exits in the submission of this manuscript, and manuscript that is enclosed is approved by all authors for publication. Neither the entire paper nor any part of its content has been published or has been accepted elsewhere. And it is not being submitted to any other journal.

\section{References}

1. Men, K.; Ai, Q.; Mai, K.; Xu, W.; Zhang, Y.; Zhou, H. Effects of dietary corn gluten meal on growth, digestion and protein metabolism in relation to IGF-I gene expression of Japanese seabass, Lateolabrax japonicus. Aquaculture 2014, 428, 303-309. [CrossRef]

2. Liying, W.; Long, D.; Ying, W.; Yan, Z.; Jingbo, L. Isolation and characterisation of in vitro and cellular free radical scavenging peptides from corn peptide fractions. Molecules 2015, 20, 3221-3237.

3. Jia, J. Effect and Mechanism of Ultrasound on Enzymatic Preparation of ACE Inhibitory Peptides from Wheat Grm Protein; Jiangsu University: Zhenjiang, China, 2009.

4. Ceren, D.; Aysun, Y.; Funda, K.G.; Hayrettin, D.; Beraat, O. Angiotensin-I-Converting Enzyme (ACE)-Inhibitory Peptides from Plants. Nutrients 2017, 9, 316.

5. Wu, S.; Qi, W.; Su, R.; Li, T.; Lu, D.; He, Z. CoMFA and CoMSIA analysis of ACE-inhibitory, antimicrobial and bitter-tasting peptides. Eur. J. Med. Chem. 2014, 84, 100-106. [CrossRef]

6. Lin, F.; Chen, L.; Liang, R.; Zhang, Z.; Wang, J.; Cai, M.; Li, Y. Pilot-scale production of low molecular weight peptides from corn wet milling byproducts and the antihypertensive effects in vivo and in vitro. Food Chem. 2011, 124, 801-807. [CrossRef]

7. Huang, W.H.; Sun, J.; He, H. Antihypertensive effect of corn peptides, produced by a continuous production in enzymatic membrane reactor, in spontaneously hypertensive rats. Food Chem. 2011, 128, 968-973. [CrossRef]

8. Zhao, C.J.; Schieber, A.; Gänzle, M.G. Formation of taste-active amino acids, amino acid derivatives and peptides in food fermentations-A review. Food Res. Int. 2016, 89, 39-47. [CrossRef] [PubMed]

9. Samaei, S.P.; Ghorbani, M.; Tagliazucchi, D.; Artini, S.M.; Babini, E. Functional, nutritional, antioxidant, sensory properties and comparative peptidomic profile of faba bean (Vicia faba, L.) seed protein hydrolysates and fortified apple juice. Food Chem. 2020, 330, 127120. [CrossRef]

10. Thielen, A.; Oueslati, M.; Hermosilla, R.; Krause, G.; Oksche, A.; Rosenthal, W.; Schülein, R. The hydrophobic amino acid residues in the membrane-proximal $C$ tail of the $G$ protein-coupled vasopressin V2 receptor are necessary for transport-competent receptor folding. FEBS Lett. 2005, 579, 5227-5235. [CrossRef] 
11. Cheung, I.W.Y.; Li-Chan, E.C.Y. Angiotensin-I-converting enzyme inhibitory activity and bitterness of enzymatically-produced hydrolysates of shrimp (Pandalopsis dispar) processing byproducts investigated by Taguchi design. Food Chem. 2010, 122, $1003-1012$. [CrossRef]

12. Pripp, A.H.; Ardö, Y. Modelling relationship between angiotensin-(I)-converting enzyme inhibition and the bitter taste of peptides. Food Chem. 2007, 102, 880-888. [CrossRef]

13. Ishibashi, N.; Kouge, K.; Shinoda, I.; Kanehisa, H.; Okai, H. A Mechanism for Bitter Taste Sensibility in Peptides. Agric. Biol. Chem. 1988, 52, 819-827.

14. Mane, S.; Damle, M.; Harikumar, P.; Jamdar, S.; Gade, W. Purification and characterization of aminopeptidase N from chicken intestine with potential application in debittering. Process Biochem. 2010, 45, 1011-1016. [CrossRef]

15. Synowiecki, J.; Jagietka, R.; Shahidi, F. Preparation of hydrolysates from bovine red blood cells and their debittering following plastein reaction. Food Chem. 1996, 57, 435-439. [CrossRef]

16. Lei, F.; Zhao, Q.; Sun-Waterhouse, D.; Zhao, M. Characterization of a salt-tolerant aminopeptidase from marine Bacillus licheniformis SWJS33 that improves hydrolysis and debittering efficiency for soy protein isolate. Food Chem. 2017, 214, 347-353. [CrossRef]

17. Abdelhedi, O.; Mora, L.; Jemil, I.; Jridi, M.; Toldra, F.; Nasri, M.; Nasri, R. Effect of ultrasound pretreatment and Maillard reaction on structure and antioxidant properties of ultrafiltrated smooth-hound viscera proteins-sucrose conjugates. Food Chem. 2017, 230, 507-515. [CrossRef] [PubMed]

18. Li, P. Study on Soybean Peptide Debitterizing and Physiological Function; University of Jinan: Jinan, China, 2014.

19. Gallego, M.; Mora, L.; Toldrá, F. The relevance of dipeptides and tripeptides in the bioactivity and taste of dry-cured ham. Food Prod. Process. Nutr. 2019, 1,1-14.

20. Huang, S.; Li, Y.; Li, C.; Ruan, S.; Roknul, A.S.M.; Ou, Y.N.; Ye, X.; Wang, Y.; Ma, H. Effects of ultrasound-assisted sodium bisulfite pretreatment on the preparation of cholesterol-lowering peptide precursors from soybean protein. Int. J. Biol. Macromol. 2021, 183, 295-304. [CrossRef] [PubMed]

21. Qu, W.; Ma, H.; Liu, B.; He, R.; Pan, Z.; Abano, E. Enzymolysis reaction kinetics and thermodynamics of defatted wheat germ protein with ultrasonic pretreatment. Ultrason. Sonochem. 2013, 20, 1408-1413. [CrossRef] [PubMed]

22. Bryan, A.; Joseph, L.; Bennett, J.A.; Jacobson, H.I.; Andersen, T.T. Design and synthesis of biologically active peptides: A 'tail' of amino acids can modulate activity of synthetic cyclic peptides. Peptides 2011, 32, 2504-2510. [CrossRef]

23. Guerard, F.; Decourcelle, N.; Sabourin, C.; Floch-Laizet, C.; Bourseau, P. Recent developments of marine ingredients for food and nutraceutical applications: A review. J. Sci. Halieut. Aquat. 2010, 2, 21-27.

24. Zhao, M.M.; Guo, S.G.; Cui, C.; Liu, T.X. Enzymatic hydrolysis of porcine hemoglobin and debittering of hydrolysates. J. Jilin Univ. 2006, 7, 941-945.

25. Adlernissen, J. Enzymic hydrolysis of food proteins. Can. Med. Assoc. J. 1986, 172, 1783-1785.

26. Actis-Goretta, L.; Ottaviani, J.I.; Keen, C.L.; Fraga, C.G. Inhibition of angiotensin converting enzyme (ACE) activity by flavan-3-ols and procyanidins. FEBS Lett. 2003, 555, 597-600. [CrossRef]

27. Minagawa, E.; Kaminogawa, S.; Tsukasaki, F.; Yamauchi, K. Debittering Mechanism in Bitter Peptides of Enzymatic Hydrolysates from Milk Casein by Aminopeptidase T. J. Food Sci. 2010, 54, 1225-1229. [CrossRef]

28. Hua, Z.; Zhen-Yu, W.; Xin, Y.; Hai-Tian, Z.; Ying-Chun, Z.; Ai-Jun, D.; Jing, J.; Jing, W. Determination of free amino acids and 18 elements in freeze-dried strawberry and blueberry fruit using an Amino Acid Analyzer and ICP-MS with micro-wave digestion. Food Chem. 2014, 147, 189-194.

29. Aissaoui, N.; Abidi, F.; Marzouki, M.N. ACE inhibitory and antioxidant activities of red scorpionfish (Scorpaena notata) protein hydrolysates. J. Food Sci. Technol. 2015, 52, 7092-7102. [CrossRef]

30. Newman, J.; Egan, T.; Harbourne, N.; Oriordan, D.; Jacquier, J.C.; Osullivan, M. Correlation of sensory bitterness in dairy protein hydrolysates: Comparison of prediction models built using sensory, chromatographic and electronic tongue data. Talanta 2014, 126, 46-53. [CrossRef] [PubMed]

31. Suh, H.J.; Whang, J.H.; Kim, Y.S.; Bae, S.H.; Noh, D.O. Preparation of angiotensin I converting enzyme inhibitor from corn gluten. Process Biochem. 2003, 38, 1239-1244. [CrossRef]

32. Ko, S.C.; Lee, J.K.; Byun, H.G.; Lee, S.C.; Jeon, Y.J. Purification and characterization of angiotensin I-converting enzyme inhibitory peptide from enzymatic hydrolysates of Styela clava flesh tissue. Process Biochem. 2012, 47, 34-40. [CrossRef]

33. Wang, X.; Liu, X.; Yang, H.; Liu, D. Preparation of ACE inhibitory peptide from corn gluten meal and pilot-scale production. Food Ferment. Ind. 2016, 42, 158-164.

34. Tsai, J.-S.; Chen, J.-L.; Pan, B.S. ACE-inhibitory peptides identified from the muscle protein hydrolysate of hard clam (Meretrix lusoria). Process Biochem. 2008, 43, 743-747. [CrossRef]

35. Tong, X.; Lian, Z.; Miao, L.; Qi, B.; Zhang, S.; Li, Y.; Wang, H.; Jiang, L. An innovative two-step enzyme-assisted aqueous extraction for the production of reduced bitterness soybean protein hydrolysates with high nutritional value. LWT 2020, 134, 110151. [CrossRef]

36. Meinlschmidt, P.; Schweiggert-Weisz, U.; Brode, V.; Eisner, P. Enzyme assisted degradation of potential soy protein allergens with special emphasis on the technofunctionality and the avoidance of a bitter taste formation. LWT Food Sci. Technol. 2016, 68, 707-716. [CrossRef] 
37. Fu, Y.; Liu, J.; Hansen, E.T.; Bredie, W.L.P.; Lametsch, R. Structural characteristics of low bitter and high umami protein hydrolysates prepared from bovine muscle and porcine plasma. Food Chem. 2018, 257, 163-171. [CrossRef] [PubMed]

38. Wu, J.; Aluko, R.E. Quantitative structure-activity relationship study of bitter di- and tri-peptides including relationship with angiotensin I-converting enzyme inhibitory activity. J. Peptide Sci. 2007, 13, 63-69. [CrossRef]

39. Jin, J. Study on Preparation of High Bioavailability Corn Protein Based on Computer Simulation and Ultrasound Assisted Proteolysis; Jiangsu University: Zhenjiang, China, 2015.

40. Ma, H.; Huang, L.; Jia, J.; He, R.; Luo, L.; Zhu, W. Effect of energy-gathered ultrasound on Alcalase. Ultrason. Sonochem. 2011, 18, 419-424. [CrossRef]

41. Yang, X.; Li, Y.; Li, S.; Oladejo, A.O.; Wang, Y.; Huang, S.; Zhou, C.; Wang, Y.; Mao, L.; Zhang, Y.; et al. Effects of low power density multi-frequency ultrasound pretreatment on the enzymolysis and the structure characterization of defatted wheat germ protein. Ultrason. Sonochem. 2017, 38, 410-420. [CrossRef] [PubMed]

42. Wang, J.J.; Zhi-He, H.U.; Zhao, Y. Using Electronic Tongue to Evaluate the Debittering Effect of Flavourzyme Treatment on Casein Hydrolysate with ACE Inhibitory Activity. Food Sci. 2013, 4, 220-224.

43. Pan, M.; Xu, F.; Wu, Y.; Yao, M.; Xiao, X.; Zhang, N.; Ju, X.; Wang, L. Application of ultrasound-assisted physical mixing treatment improves in vitro protein digestibility of rapeseed napin. Ultrason. Sonochem. 2020, 67, 105136. [CrossRef] [PubMed]

44. Zhou, C.; Hu, J.; Yu, X.; Yagoub, A.E.A.; Zhang, Y.; Ma, H.; Gao, X.; Out, P.N.Y. Heat and/or ultrasound pretreatments motivated enzymolysis of corn gluten meal: Hydrolysis kinetics and protein structure. LWT 2017, 77, 488-496. [CrossRef]

45. Ney, K.H. Prediction of bitterness of peptides from their amino acid composition. Z. Lebensm. Unters. Forsch. 1971, 147, 64-68. [CrossRef] 